\title{
Política exterior e relações internacionais do Brasil: enfoque paradigmático
}

\author{
AMADO LUIZ CERVO*
}

\section{Introdução}

A teoria das relações internacionais, uma disciplina que já foi considerada norte-americana, expandiu-se por centros de estudo em todo mundo. Nossas livrarias exibem manuais que expõem escolas de pensamento ou correntes de interpretação, oriundas de grupos localizados nos mais diversos países. ${ }^{1}$ Em muitas Universidades, particularmente no Brasil, ainda se confere lugar privilegiado aos autores norte-americanos. A influência que deriva sobre a opinião e o modo de ver o tema, salutar por um lado, visto haver-se desenvolvido nos Estados Unidos a reflexão mais consistente sobre as relações internacionais desde a Segunda Guerra Mundial, comporta riscos pedagógicos, por outro.

Toda teoria envolve uma visão de dentro das relações internacionais, porque veicula valores, desígnios e interesses nacionais. Por tal razão, uma teoria alheia pode ser epistemologicamente inadequada para explicar as relações internacionais de outro país e, ainda, ao informar o processo decisório, pode ser politicamente nociva. Tomemos dois exemplos elementares. Se o choque de civilizações, com que Samuel Huntington vê o mundo posterior à Guerra Fria, ou o dilema de segurança, com que R. Jervis interpreta os problemas da paz e da guerra, convêm como categorias explicativas e inspiração prática para os acadêmicos ou decisores norte-americanos, por óbvio, não convêm aos brasileiros nem como explicação das relações internacionais do país, muito menos como referências para o processo decisório $^{2}$. O conhecimento das relações internacionais compõe o poder como instrumento útil. Para mentes críticas exerce, conseqüentemente, função preventiva diante de ameaças externas da parte de homens de Estado que tiram inspiração de formulações introspectivas, derivadas de culturas ou interesses nacionais.

Essas considerações comprovam a necessidade que tem cada país de destilar teorias alheias e de partir para construções teóricas que sejam epistemológicamente adequadas e socialmente úteis. A América Latina delas

Rev. Bras. Polít. Int. 46 (2): 5-25 [2003]

* Professor Titular de Relações Internacionais da Universidade de Brasília. Publicação autorizada pelo Instituto Rio Branco. 
dispõe. Duas são as versões do pensamento latino-americano aplicado às relações internacionais: a que expõem pensadores voltados para a realidade regional das relações internacionais e a que elaborou-se dentro dos gabinetes dos formuladores de políticas e foram historicamente aplicadas.

A primeira corrente, à raiz dos estudos de Raúl Prebisch, envolve o pensamento do grupo reunido pela Comissão Econômica para a América Latina (Cepal), desde sua criação ao final da década de 1940. Esse grupo inspirou derivações expressas por Celso Furtado em sua teoria do desenvolvimento e pelos enfoques da dependência elaborados sobretudo nos anos 1960 e 1970, por Theotonio dos Santos, Ruy Mário Marini e Fernando Henrique Cardoso entre outros. O pensamento neoliberal irrompeu nos anos 1980 e foi expresso com vigor pela comunidade epistêmica argentina na década seguinte, quando a própria Cepal adaptou seu modo de ver as relações internacionais regionais, inventando a versão do regionalismo aberto. A essa altura, contudo, o pensamento cepalino, precursor das versões estruturalistas das teorias do desenvolvimento e da dependência, também operava seu aggiornamento, dando origem à correntes neoestruturalista de Osvaldo Sunkel e Raúl Bernal-Meza e ao pensamento crítico acerca da globalização, exposto nas obras de Mario Rapoport, Roberto Lavagna e Aldo Ferrer. O componente mental diretor dessa corrente latino-americana foi e continua sendo o estruturalismo. Uma síntese da teoria latino-americana das relações internacionais está sendo preparada por Raúl Bernal-Meza ${ }^{3}$.

A segunda corrente do pensamento latino-americano os estudiosos deduzem da prática política, ao dela sacar conceitos, por vezes elaborados pelos homens de Estado, por vezes implícitos em sua práxis. A análise paradigmática que aplicamos em nossos estudos recentes acerca das relações internacionais do Brasil e da América Latina revelou-se um método criador de conceitos instrumentais, cujo conjunto conduz à teoria ${ }^{4}$.

Nesse texto, expomos, pois, uma reflexão acerca da política exterior e das relações internacionais do Brasil, com o objetivo de elaborar os conceitos que lhes dão inteligibilidade orgânica e fornecem, ao mesmo tempo, critérios de avaliação de resultados.

\section{Componentes de um conceito paradigmático}

Um paradigma, em ciências humanas e sociais, equivale a uma explanação compreensiva do real. O uso que dele fazem as ciências exatas e naturais é diferente. Nessas últimas, o paradigma articula em uma teoria uma série de leis científicas que estabelecem, em princípio, relações necessárias de causa e efeito. Quando uma lei é rejeitada pela experiência, o paradigma cai. Nas ciências humanas, o paradigma também desempenha a superior função de organizar a matéria objeto de observação, porém não apresenta a mesma rigidez científica. 
Esse tido de análise, nas ciências humanas, restringe-se à função de dar inteligibilidade ao objeto, iluminá-lo através de conceitos, dar compreensão orgânica ao complexo mundo da vida humana. Em razão dessa versatilidade e flexibilidade, não deve o leitor exigir de um paradigma o encaixe de todas as variáveis, dependentes, independentes ou intervenientes, na explicação de um tema de estudo.

A análise paradigmática que aplicamos a nosso objeto de estudo, as relações internacionais do Brasil, corresponde, antes de tudo, a um método. Temos por fim a construção de conceitos pela via da observação empírica. A história constitui o campo de observação, o laboratório de experiências sobre as quais nos inclinamos. Coletamos as experiências históricas, da Independência a nossos dias, em três níveis, o diplomático, o político e o das relações internacionais, já que nosso método pressupõe a articulação dessas três dimensões da base empírica de observação.

Assim conduzida, a análise paradigmática evoca, com efeito, determinados pressupostos. Em primeiro plano, por trás de um paradigma, verificamos a existência de idéia de nação que um povo - ao menos seus dirigentes - faz de si mesmo, a visão que projeta do mundo e o modo como percebe a relação entre esses dois elementos. Tais pressupostos nos levam ao conjunto de valores cultivados, ou seja, à identidade cultural, que condiciona os desígnios duradouros da política exterior. O paradigma comporta uma cosmovisão, a imagem que uma determinada formulação conceitual projeta dos outros povos, nações ou do mundo todo.

Em segundo plano, o paradigma comporta percepções de interesse. A leitura que os dirigentes fazem dos interesses nacionais - sociais, políticos, de segurança, econômicos, culturais - modifica-se com a mudança do paradigma.

Em terceiro plano, o paradigma envolve a elaboração política. Nesse sentido, condiciona tendências de médio ou longo prazos, como também explica suas rupturas. Ou seja, envolve o modo de relacionar o interno ao externo e a manipulação da informação para estabelecer o cálculo estratégico e a decisão.

A análise paradigmática converge, enfim, para dois tipos de resultados. Dela se espera, por um lado, o efeito cognitivo, uma vez que o paradigma organiza a matéria, sempre complexa, difusa e disparatada quando se trata do comportamento humano, conferindo-lhe o grau possível de inteligibilidade orgânica. Existe, por outro, o efeito operacional. Um paradigma inclui um modo de proceder, no caso, de fazer política exterior ou de controlar as relações internacionais. A análise paradigmática há de colher as determinações internas e os condicionamentos externos, os fins da política, o peso da idéia de nação a construir e da cosmovisão. Tomado como referencial, o paradigma vigente permite avaliar o desempenho dos dirigentes e da sociedade organizada. A produção de um conceito paradigmático pressupõe a longa duração, porque sobre ela se aplica naturalmente, não servindo à análise de conjunturas, a não ser a reverso, na medida em que essas conjunturas do tempo curto nele encontrem sua localização cognitiva e operacional. 
Os países abrigam sempre suas políticas exteriores e seu modelo de inserção internacional dentro de paradigmas. Tomemos exemplos, cujo grau de elaboração não cabe discutir aqui, com a simples finalidade de ilustrar o conceito. A União Soviética esteve sob a tentação de mover-se em função da revolução transnacional ou do interesse concreto nacional. Os Estados Unidos descobriram seu manifest destiny, como a França de De Gaulle seu grand dessein. Durante a segunda metade do século XX, observamos os paradigmas globais da Guerra Fria e da coexistência pacífica. O Japão, após a Segunda Guerra Mundial, situouse sob o guarda-chuva nuclear norte-americano e construiu sua potência com base na cooperação econômica regional e na internacionalização de suas empresas. A China transitou da relação especial com a União Soviética para o confronto, a teoria dos três mundos, dos dois mundos e, enfim, para a realização de interesses concretos de seu desenvolvimento. A Argentina de Juan Domingo Perón avançou sua Terceira Posição.

Quando orientações externas dessa natureza são pesquisadas, utilizandose o método aqui proposto, podem converter-se conceitualmente em paradigmas de política exterior e relações internacionais dos respectivos países ou grupo de países.

As relações internacionais do Brasil deram origem a quatro paradigmas: o liberal-conservador que se estende do século XIX a 1930, o Estado desenvolvimentista, entre 1930 e 1989, O Estado normal e o Estado logístico, sendo que os três últimos coexistem e integram o modelo brasileiro de relações internacionais, de 1990 a nossos dias. Identificamos e definimos essas experiências à luz dos pressupostos metodológicos e epistemológicos que definimos anteriormente.

Com o objetivo de elaborar conceitos claros e de poder compará-los entre si, selecionamos para os quatro paradigmas idênticos componentes teóricos que aplicamos ao estudo de cada caso, como se fossem critérios de definição. Primeiramente, buscamos as origens do paradigma. Quais as causas, internas e externas, que se encontram em sua gênese? Que fatores explicam sua continuidade e que outros preparam a transição para novo paradigma? Procedemos, a seguir, à identificação de seus parâmetros. Julgamos conveniente distinguir dois conjuntos de componentes do paradigma, o bloco mental, composto de ideologia e política, e o bloco duro, composto de percepção de interesses nacionais, relações econômicas internacionais e impactos sobre a formação nacional.

\section{O paradigma liberal-conservador do século XIX e da Primeira República (1810-1930)}

Os estudos de Adam Watson, Hedley Bull e Brunello Vigezzi acerca da sociedade internacional européia do início do século XIX e do sistema internacional dela decorrente constituem adequado ponto de partida para entender o secular 
paradigma liberal-conservador implementado pelos países da América Latina desde suas independências 5 .

Pela primeira vez na História, um sistema internacional de escala global estendeu-se sobre o planeta, a partir de valores, princípios e interesses europeus. A sociedade internacional européia vinha sendo erguida na esfera política, desde o congresso de Vestefália de 1644, homogeneizando instituições, mas foi a superioridade econômica dos europeus, advinda do avanço relativamente aos outros povos, que acabou por convertê-la em sistema internacional universal. Por essa razão, o sistema internacional vigente no século XIX, feito de regras de conduta padronizadas, converteu-se em poderoso instrumento de expansão dos interesses das potências capitalistas européias.

Os europeus impuseram à periferia do capitalismo, à América Latina, ao Império Otomano e ao continente asiático, em um primeiro momento, à África negra ao final do século, o modo de fazer comércio, de organizar à produção e até mesmo de criar instituições políticas e sociais. Eram os tratados bilaterais de então o instrumento desse ordenamento jurídico, político e econômico. O Brasil firmou com as potências capitalistas cerca de duas dezenas deles, entre 1810 e $1828^{6}$.

O conteúdo essencial do modelo de relações internacionais definido pelos europeus era a chamada política das portas abertas. A periferia não tinha opção, quando firmava tratados: abria seu mercado aos manufaturados europeus e voltavase para atividades primárias. O liberalismo europeu continha apenas uma face, para fora. Os países europeus somente aceitarão o liberalismo para dentro quando dispuserem de vantagens comparativas intangíveis, como o conhecimento, a tecnologia e a organização empresarial. A economia ricardiana, de prevalência do livre comércio, primeiro na periferia e depois no centro, induziu, desse modo, a divisão internacional do trabalho, na qual a periferia, como a América Latina, voltava-se para relações em que prevaleciam as vantagens comparativas de tipo natural. Centro e periferia submeteram-se, como evidencia a pesquisa dos latinoamericanos desde 1950, a funções complementares que reproduziriam simultaneamente as condições de desenvolvimento e de subdesenvolvimento.

Os negociadores brasileiros dos tratados da época da independência cogitaram em fazer valer os direitos dos plantadores e exportadores de produtos primários, mas nem mesmo estes foram aceitos pelos negociadores europeus, cujos mercados admitiam tão somente os produtos oriundos da colônia respectiva. Os brasileiros cederam, portando, o mercado de manufaturados, bloqueando a modernização capitalista interna, em troca de nada. O grupo socialmente hegemônico irá beneficiar-se, com o tempo, desse esquema de intercâmbio, quando a diplomacia brasileira, a duras penas, abriu mercados para os produtos da agroexportação. Sem isso, o afã de consumo de manufaturados por parte dos proprietários de terras, apesar das baixas tarifas de importação fixadas pelos tratados, dificilmente se verificaria. 
A ideologia que os dirigentes brasileiros esposaram no século XIX era o liberalismo de matriz européia. Esse liberalismo estendia-se à construção das instituições políticas do Estado monárquico e, depois, do republicano, como à organização da sociedade, exceção feita ao regime da escravidão. O liberalismo determinava o modo de se organizar a produção, de se fazer o comércio e de portar-se com o exterior, nos domínios das finanças e do comércio. A ideologia liberal está presente sobretudo à época da Regência (1831-1840) quando se moldam as instituições do Estado nacional e se trava a grande polêmica em torno da centralização e descentralização do poder. Está presente na década de 1840, ao expirarem os tratados desiguais da época da Independência, quando se trava outro debate acirrado entre livre-cambistas e protecionistas em torno da política alfandegária e de comércio exterior. Prevalece durante a segunda metade do século XIX e durante a Primeira República na mentalidade do grupo social que detinha o poder econômico e configurava o político.

As manifestações políticas da ideologia liberal-conservadora foram coerentes, sem deixar, contudo, de exibir algumas contradições. A face liberal explica a assinatura dos tratados desiguais e, depois deles, a política aduaneira, ou seja o fato de estabelecer-se o Brasil na condição periférica de modo permanente. A face conservadora explica o malogrado projeto de industrialização dos anos 1840, a determinação de exercer um certo controle sobre o subsistema platino de relações internacionais e a negociação firme das fronteiras do território nacional. Subserviência e soberania temperavam a política exterior e o modelo de inserção internacional do país na vigência do paradigma liberal-conservador, com inclinação prevalecente da primeira tendência na esfera econômica e da segunda na esfera política e geopolítica.

O bloco duro das relações internacionais do país, da independência a 1930 inclui, como vimos, a percepção dos interesses nacionais, as relações econômicas internacionais e os impactos sobre a formação nacional.

Os liberais-conservadores brasileiros procediam à leitura do interesse nacional, evocando um conceito de sociedade simples, composta fundamentalmente de dois segmentos: os grandes proprietários das terras e donos do poder, e o resto da sociedade, fossem escravos, ex-escravos, trabalhadores livres, imigrantes. Uma sociedade estabelecida em sua infância, feita de plantadores e exportadores de café, açúcar e outros pequenos produtos da terra, que a nada mais aspirava, nas amargas palavras do senador da Monarquia, Sales Torres Homem. Aqueles dirigentes confundiam, logicamente, o interesse nacional com os próprios interesses, ou seja, os do grupo sócio-econômico hegemônico: dispor de mão-de-obra, exportar os frutos da lavoura e importar bens de consumo diversificados. A diplomacia da agroexportação, conceito elaborado por Clodoaldo Bueno, não explica toda a política exterior do Brasil, mas retrata a essência da funcionalidade do Estado na área externa. Tendo sido apropriado pelas elites sociais, o Estado manobrava um processo 
decisório em política exterior voltado, primordialmente, àquela leitura restrita do interesse nacional que fazia.

Compreendemos, assim, o esquema de relações econômicas internacionais a que se submeteu o Brasil durante bem mais de um século: exportações primárias e importações industriais, prestígio externo como convinha a oligarquias de dominação interna e crédito junto à praça de Londres para enfrentar eventuais problemas de balanço de pagamentos.

Os impactos sobre a formação nacional são bem conhecidos de nossos historiadores. Ilusão de modernidade em ilhas urbanas de consumo ou fazendas interioranas e atraso econômico da nação. Os analistas da Cepal elaboraram conceitos tardios acerca do acoplamento dependente centro-periferia que alimentava simultaneamente o desenvolvimento e o subdesenvolvimento, como se fossem verso e reverso de idênticos mecanismos. Houve, contudo, homens de Estado e mentes esclarecidas que, desde a época da Independência, protestavam contra o modelo de inserção internacional que mantinha o país à margem do progresso capitalista. Nícia Vilela Luz retratou a luta pela industrialização. Foi intermitente e inglória essa luta, desde o projeto de D. João VI em 1808, a reação do Parlamento, desde 1827, contra os tratados desiguais, o livrinho de Nicolau de Araújo Vergueiro sobre a fábrica de ferro de Ipanema, escrito em 1828, a irrupção do pensamento industrialista nos anos 1840, o debate entre industrialistas e liberais radicais por ocasião da votação da lei aduaneira, enfim, a revolta de intelectuais, tenentistas, modernistas e outros na década de $1920^{7}$.

\section{O paradigma do Estado desenvolvimentista entre 1930 e 1989}

Durante os anos da depressão capitalista e no contexto da Segunda Guerra Mundial, a América Latina revelou extraordinário dinamismo econômico que trouxe ao mundo moderno os grandes países como o Brasil, o México e a Argentina. Impactos externos e internos agiam como elementos propulsores da transformação. No caso do Brasil, os de fora foram a queda de importações e exportações devida à crise econômica dos anos 1930, a disputa pelo mercado e pelo sistema produtivo da parte das potências capitalistas, a divisão do mundo em blocos e a política norte-americana de boa vizinhança de Franklin D. Roosevelt. Por dentro, assistiase ao despertar de novas forças que requeriam a modernização. A depressão, paradoxalmente, conduziu os países capitalistas avançados de regresso ao protecionismo e a soluções nacionalistas e a América Latina a um processo de modernização.

Os impulsos internos advinham especialmente dos que criticavam a dependência e o atraso histórico e das demandas de uma sociedade que se havia transformado. Massas urbanas a requerer emprego e renda, burguesia nacional ávida por oportunidades de negócios, militares a procura de meios com que prover 
a segurança, intelectuais e políticos de mentalidade revolucionária. Manobrar em meio à divisão do mundo em blocos foi uma possibilidade concreta que perceberam os novos dirigentes, conduzidos ao poder por eleições, como no México e na Argentina, ou por uma revolução, como a de 1930 no Brasil.

As condições para a gênese de novo paradigma de relações internacionais estavam assentadas. Os dirigentes rompem com a diplomacia da agroexportação e conferem nova funcionalidade ao Estado, contando com o apoio do pensamento diplomático, da imprensa e da opinião pública popular.

A mudança paradigmática dos anos 1930-40 ocorreu como se fosse um movimento latino-americano. Traços comuns a diversos países da região fornecem os componentes teóricos do novo modelo de inserção internacional: a) introduzir a diplomacia econômica nas negociações externas; b) promover a indústria por modo a satisfazer às demandas da sociedade; c) transitar da subserviência à autonomia decisória com o fim de realizar ganhos recíprocos nas relações internacionais; d) implementar projeto nacional de desenvolvimento assertivo tendo em vista superar desigualdades entre nações; e) cimentar o todo pelo nacionalismo econômico, imitando a conduta das grandes potências.

O paradigma em construção apresenta, pois, um perfil caracterizado por três componentes: a) consciência da transição; b) desenvolvimento como vetor da política exterior; c) realismo de conduta. E confere nova funcionalidade ao setor externo, inventando o modelo de inserção internacional: a) realizar interesses de uma sociedade complexa; b) conceber o desenvolvimento como expansão da indústria; c) prover de eficiência a política exterior mediante autonomia decisória, cooperação externa, política de comércio exterior flexível e não doutrinária, subordinação da política de segurança, da guerra e da paz, aos fins econômicos e negociação simultânea com os grandes e os vizinhos.

Embora tenham sido lançados e definidos com bastante clareza durante a depressão capitalista e a Segunda Guerra Mundial, os parâmetros do paradigma desenvolvimentista seriam depurados e aperfeiçoados nas décadas seguintes, integrando, assim, o modelo de inserção internacional para o país por um período de sessenta anos. Expomos, a seguir, essa evolução para a maturidade.

O bloco mental do paradigma desenvolvimentista compõe-se de uma variável ideológica e outra política. Irrompeu, por certo, na América Latina, e com maior força no Brasil, a ideologia desenvolvimentista, que penetrou a opinião pública, a vida política e os estudos sócio-econômicos, entre os anos 1950 e 1980. Os homens de Estado mais contaminados por essa ideologia foram Getúlio Vargas, Juscelino Kubitschek e Ernesto Geisel. Entre os intelectuais construtores do desenvolvimentismo figuram Raúl Prebisch, Celso Furtado, Aldo Ferrer, Theotonio dos Santos, Ruy Mauro Marini, Roberto Lavagna, Mario Rapoport, Raúl BernalMeza, Osvaldo Sunkel. 
A vertente desenvolvimentista desse pensamento latino evoluiu, desde as formulações do grupo da Cepal, que elaborou nos anos 1950 uma teoria originalmente inspirada na prática política de Vargas, entre 1930 e 1945. Dos conceitos originais de Prebisch - centro-periferia, indústria, mercado interno, renda salarial, deterioração dos termos de troca - à teoria do desenvolvimento de Celso Furtado, que insiste sobre o componente da desigualdade tecnológica, a corrente chega aos enfoques dependentistas dos anos 1960 e 1970, que aprofundam o estudo da relação entre dominação e dependência, por meio da análise estrutural. Tudo será referido ao conceito de poder nas relações internacionais por Osvaldo Sunkel e, por Ferrer, à estratégia de conduzir-se por vantagens comparativas naturais (América Latina) ou intangíveis (países desenvolvidos).

A teoria latino-americana das relações internacionais, na expressão de Bernal-Meza, comporta, em nosso entender, como elementos ideológicos, além do desenvolvimentismo acima definido, o liberalismo e o ocidentalismo, bem como a cultura da democracia. A variável política do bloco mental que compõe o paradigma sob análise volta-se para a superação da assimetria capitalista pela promoção do desenvolvimento e pressupõe a autonomia decisória, sem o que nada se alcança nessa via.

Durante décadas, a ideologia desenvolvimentista fez a unanimidade no Brasil, mas não fez o entendimento político. Dividiram-se dirigentes e intelectuais brasileiros, como também as correntes de opinião pública, em torno do modelo de desenvolvimento a implementar. $\mathrm{O}$ desenvolvimento associado às forças externas do capitalismo, de estreitos vínculos políticos, geopolíticos e econômicos com a matriz do sistema, os Estados Unidos, tido por recomendável por Eurico Gaspar Dutra (1946-1950), Castelo Branco (1964-1967), Fernando Collor de Melo (19901992) e Fernando Henrique Cardoso (1994-2002). O desenvolvimento autônomo, tocado essencialmente pelas forças da nação, criador de autonomia política e de forte núcleo econômico, tido por recomendável por Getúlio Vargas, João Goulart e Ernesto Geisel. Essas duas estratégias, na verdade, não abriram guerra entre si, como ocorreu na Argentina, ao contrário, proveram pelo diálogo e pela interpenetração, um modelo misto de desenvolvimento, fechado e aberto em doses equilibradas. Racional e de fôlego no tempo longo.

Concluída a definição dos parâmetros mentais do paradigma desenvolvimentista, resta-nos examinar os do bloco duro.

A percepção dos interesses nacionais dos desenvolvimentistas, autoridades, profissionais e intelectuais, trabalha com o conceito de sociedade complexa, em transformação, rumo ao progresso econômico. Essa nova leitura deixa para trás o conceito de sociedade simples, composta de apenas dois estratos, que comandava as decisões de liberais-conservadores no passado. Desde a era Vargas, consignouse ao Estado satisfazer necessidades de empresários, industrialistas, agricultores, 
operários, camponeses, militares e outros segmentos. Lidava-se, portanto, com um conceito de interesse nacional múltiplo, cabendo à diplomacia, nas relações exteriores, equacionar a soma de interesses segmentados, cujas exigências por vezes colidiam, tendo em mente o destino da nação.

O desenvolvimento correspondia ao conceito operativo destinado a balancear a funcionalidade do Estado. Tornou-se o vetor da política exterior. A acepção do desenvolvimento, conceito sociológico complexo, por abranger o econômico e o social, restringiu-se, na mente dos tomadores de decisão, por modo a contemplar essencialmente duas variáveis: a industrialização e o crescimento econômico. A industrialização, porque por meio dela julgava-se preencher as demandas da sociedade complexa, empurrando o conjunto em direção à modernidade do capitalismo. O elevado ritmo de crescimento, porque por meio dele recuperar-se-ia o atraso histórico. A política exterior destinava-se a preencher requisitos desse desenvolvimento assim concebido, trazendo de fora três insumos em apoio aos esforços internos: capital complementar à poupança nacional, ciência e tecnologia e mercados externos, com que transitar da substituição de importações à substituição de exportações.

O paradigma surtiu efeitos articulados em três fases sucessivas, de forma não muito rígida, porém suficientemente diferenciadas: a fase de implantação de uma grande indústria de transformação, obra dos anos 1950 e 1960 e do empreendimento estrangeiro, a fase de implantação da indústria de base, consolidada nos anos 1970 a partir de empreendimentos pioneiros do Estado já existentes, e a fase de inovação tecnológica em alguns setores de ponta, iniciada nos anos 1970 pelos setores de atividade, tanto o público quanto o privado, e continuada nas décadas a seguir.

Não obstante haver desencadeado permanente polêmica acerca do grau de abertura, no longo prazo, a estratégia de desenvolvimento entendeu a abertura, tanto do sistema produtivo quando do mercado de consumo, como categorias decisórias funcionais: maior ou menor grau de abertura a empreendimentos ou produtos externos eram dosados pelo impacto que produziriam sobre o desenvolvimento em si. Assim, poderia convir maior proteção a um setor de atividades, a determinado segmento do mercado, bem como ao conjunto do sistema produtivo com o fim de induzir sua expansão pelo empreendimento nacional ou estrangeiro.

Os impactos do paradigma desenvolvimentista sobre a formação nacional foram de natureza a romper o modelo de dependência acoplada centro-periferia, conceituado pelo pensamento estruturalista de matriz cepalina. Tiveram razão, portanto, os pensadores estruturalistas que sugeriam mecanismos de superação de assimetrias internacionais navegando no próprio sistema capitalista, contra os teóricos da dependência que sugeriam saltar fora do sistema para atingir os mesmos resultados. 
A estratégia desenvolvimentista manteve-se durante décadas e por certo requeria esse tempo longo para conduzir o país a outra fase de sua história, o que fez em sessenta anos ${ }^{8}$.

\section{O paradigma do Estado normal (1990-2002)}

O paradigma do Estado normal foi a grande invenção da inteligência política latino-americana da década de 1990. Irrompeu com tamanha força, coerência e convergência regional entre os países, que nada se lhe compara em outras partes do mundo. As origens não foram apenas externas, como por vezes se supõe, ou seja, a miragem de uma globalização benigna e as recomendações do centro do capitalismo. Uma vertente do pensamento latino-americano sobreviveu à prevalência do estruturalismo cepalino e aflorou ao final do século XX.

Desde os anos 1950, com efeito, registravam-se experiências monetaristas de governo, efêmeras sempre, caracterizadas por estratégia alheia aos pressupostos das políticas desenvolvimentistas. De fato, um dos problemas crônicos enfrentados pelos dirigentes latino-americanos foi o da estabilidade econômica, perturbada pela inflação. Os estruturalistas entendiam que haveria de superar-se com medidas de longo prazo, ao passo que os monetaristas estavam inclinados ao tratamento de choque.

Em 1989-90 elegeram-se presidentes neoliberais em todos os grandes Estados da América Latina e os monetaristas, de formação norte-americana em sua grande maioria, alojaram-se nos postos decisórios. Tratamentos de choque, de corte neoliberal, foram aplicados pelos governos de Augusto Pinochet no Chile, Carlos Saúl Menem na Argentina, Alberto Fujimori no Peru, Carlos Andrés Pérez na Venezuela, Fernando Collor de Melo no Brasil, e Carlos Salinas de Gortari no México. Era o triunfo do monetarismo sobre o estruturalismo, no pensamento e na práxis. Os detentores desse chamado pensamento único partiram em guerra contra a estratégia de indução do desenvolvimento pela via assertiva das políticas de Estado. Assim como antes se havia operado uma redução do conceito de desenvolvimento para o de expansão industrial e crescimento econômico, operouse agora outra redução, a da funcionalidade do Estado. Para os monetaristas, consignava-se ao Estado a função de prover a estabilidade econômica, logo reduzida à estabilidade monetária, e ao mercado todo o mais, a promoção do próprio desenvolvimento, por suposto.

A corrente de pensamento monetarista de matriz neoliberal reforçou-se quando a própria Cepal fez autocrítica. Ela adaptou seu pensamento, cedendo às circunstâncias imperantes e formulando a doutrina do regionalismo aberto, uma versão mais inclinada para o lado do neoliberalismo do que do estruturalismo desenvolvimentista. 
Experiências neoliberais hispano-americanas precederam a brasileira, mesmo porque o Brasil avançara mais que todos os outros países da região pelo caminho do desenvolvimento, convertendo-se na oitava potência econômica do mundo, com um parque industrial moderno e uma agricultura competitiva. Saltar desse paradigma histórico que tão concretos e profícuos efeitos assegurara, para outro, não era uma decisão estratégica fácil de tomar. Mas o exemplo provocativo da vizinhança aguçou os mentores de mudança e o governo brasileiro acabou por aceitar a tendência da moda.

As determinações externas constituem outro fator de peso na gênese do Estado normal. Com efeito, o endividamento latino-americano dos anos 1980, cujo aumento deveu-se à elevação das taxas de juro durante os mandatos de Ronald Reagan, converteu os países da região em grandes esmoleiros internacionais. A busca desenfreada de recursos externos abriu uma porta pela qual os comandos passariam. O denominado Consenso de Washington conjugou-se com exigências do Banco Mundial, do Fundo Monetário Internacional e dos governos, sobretudo o norte-americano. Os dirigentes da América Latina haveriam de seguir as instruções do centro, sem o que os empréstimos não seriam concedidos.

O conjunto dessas instruções dizia respeito à abertura dos mercados de consumo, abertura dos mercados de valores, abertura do sistema produtivo e de serviços, eliminação do Estado empresário, privatizações, superávit primário, proteção ao capital e ao empreendimento estrangeiros e adaptação das instituições e da legislação por modo a produzir esse novo ordenamento. Ser normal, na feliz expressão de Domingo Cavallo, Ministro de Relações Exteriores do governo de Menem, significava dar cumprimento a esse conjunto de instruções. Ser normal converteu-se na aspiração de praticamente todos os governos latino-americanos a partir de 1989-90. Competiam, aliás, entre si, nesse afã de ser normal, aplicando tratamentos de choque com evidente intuito exibicionista.

De um ponto de vista ideológico e também político, nenhum país revelou mais coerência e consistência do que a Argentina na adoção do novo paradigma. O aparecimento de uma comunidade epistêmica, composta de intelectuais, jornalistas, diplomatas, empresários, legisladores e dirigentes causou profunda impressão nos países vizinhos, enfraquecendo no Brasil as resistências à mudança que se operava. A experiência Argentina constituiu, portanto, mais um fator explicativo da origem do paradigma normal.

No Brasil, o pensamento e a prática política de Fernando Henrique Cardoso nortearam a nova fase. Seus numerosos escritos evidenciam o impacto das circunstâncias que o elevaram à condição de teórico brasileiro do pensamento único. Seu conceito de mudança, implacável estratégia sem alternativa, e de circunstâncias imperantes, mecanismos de causalidade necessária, transformados em padrão de conduta de Estado, introduziram a era Cardoso, que se estendeu de 
1993 a 2002, embora nela possamos incluir o governo do primeiro Fernando, de 1990 a 1992. Teríamos, assim, uma era Cardoso longa, entre 1990 e 2002.

Entendida a origem do Estado normal, examinemos seus parâmetros, iniciando pelos que compõem o bloco mental.

O pensamento neoliberal reformulou a economia política clássica e a keynesiana, alçando-se em nova doutrina econômica e política com Milton Friedman. Os neoliberais sugeriam um choque de mercado para reanimar o cambaleante capitalismo da época da Guerra Fria. Margaret Thatcher e Ronald Reagan deram-lhes ouvido. Desencadeava-se, desse modo, nova onda, que tomou vulto com o fim da União Soviética e o colapso do socialismo real. Penetrou a América Latina pela via do pensamento monetarista e do regionalismo aberto da Cepal. Os neocepalinos propunham uma simbiose, combinando abertura ampla da economia, requerida pela globalização, com integração bilateral ou regional, feita de preferências comerciais por modo a controlar eventuais efeitos negativos da abertura.

Essas circunstâncias não explicam, contudo, o substrato ideológico do paradigma normal, a invenção latino-americana. Isso porque, em sua base, viceja, para além da ideologia, uma crença. O neoliberalismo transformou-se na América Latina em mais um fundamentalismo típico do fim do século $\mathrm{XX}$, quando aparentemente o conflito ideológico amainava em todo o mundo. Misto de crença, fé e utopia, esse fundamentalismo pouco carregava de ciência em seu bojo. $\mathrm{O}$ pensamento de Cardoso e sua equipe - "mudam-se os tempos”, "tempos de mudança”, expressões estampadas em títulos de livros por eles publicados - está mais para o catecismo e a igreja do que para o manual e a academia ${ }^{9}$. Seus textos e sua prática política revelam, com efeito, a fé em fórmulas convencionais do credo neoliberal, fé sobretudo no império do mercado como indutor do desenvolvimento.

Converter o substrato ideológico e religioso do paradigma normal em padrões de comportamento político exigia, sim, boa dose de racionalidade, de que não careciam os homens de Estado brasileiros da era Cardoso. O elo estabeleceuse, pois, da doutrina à política, da ideologia à política e da crença à política. O que para a mais elementar análise crítica é um enigma, para os estrategistas normais é coerência. Adotar, por exemplo, a abertura econômica como estratégia, sem nenhuma estratégia de inserção adequada no mundo da interdependência global ${ }^{10}$. Sacrificar a autonomia decisória aos comandos do centro capitalista, simplesmente porque suas instruções erigiam o império do mercado.

O bloco duro do paradigma normal - percepção dos interesses nacionais, relações econômicas internacionais e impactos sobre a formação nacional - reserva outras surpresas ao analista.

Os dirigentes normais esterilizaram, de pronto, duas idéias-força do paradigma desenvolvimentista: as idéias de interesse nacional e de projeto nacional 
de desenvolvimento. Pedro Malan, o poderoso Ministro da Fazenda da era Cardoso, declarou que um país como o Brasil não poderia sonhar com projeto nacional, algo reservado apenas a grandes potências. No mundo da globalização, entendiam aqueles dirigentes, interesses nacionais se diluem na ordem tecida pelo ordenamento multilateral das relações internacionais, a chamada governança global. Política exterior tornava-se conceito fora de moda, mero ornamento da ação do Estado, visto que não se lhe consignava mais a realização de interesses concretos. Por isso mesmo, durante a era Cardoso, o Itamaraty trocava amiúde de ministro ou mantinha por vários anos quem não manifestasse vontade forte ou pensamento próprio.

As relações econômicas internacionais do Brasil, promovidas pelos estrategistas normais, encaminharam a destruição do patrimônio nacional construído em sessenta anos de esforços. Os mecanismos de privatização das empresas públicas, exigida pelo centro de comando capitalista, foram além das instruções recebidas, ao dar preferência ao capital e às empresas estrangeiros. A abertura do mercado financeiro e dos bancos adaptou-se, porém, àquelas instruções, que garantiam o livre fluxo de capitais especulativos. A especulação e a alienação de ativos de empresas privatizadas ou de empresas privadas vendidas ao exterior abriram, naturalmente, duas novas vias de transferência de renda ao centro, que se somaram à tradicional via dos serviços da dívida externa. A renda do país passou a migrar para fora também pela via dos dividendos e do movimento de capitais. Os normais não pensaram em remédios de equilíbrio a tais mecanismos, a não ser a busca desenfreada de capitais com que enfrentar o déficit das contas. Viviam da ilusão de divisas, ao tempo em que dilapidavam o patrimônio nacional.

Sem projeto de desenvolvimento e sem recursos, a era Cardoso, era dos normais, provocou a estagnação da economia brasileira e interrompeu um ciclo de sessenta anos de desenvolvimento caracterizado pelas mais elevadas taxas de crescimento entre os países do mundo capitalista.

Os impactos do Estado normal sobre a formação nacional são percebidos de três maneiras, uma positiva e duas negativas. O choque da abertura despertou empresários brasileiros do setor público e privado, acomodados que andavam ao abrigo de um protecionismo exacerbado a que havia conduzido o paradigma anterior. O mercado interno, amplo e reservado, lhes bastava então. Com a abertura, para fazer face à inundação de produtos estrangeiros, foram forçados a modernizar suas plantas e métodos. A resposta foi positiva e, desse modo, o choque da abertura contribuiu para elevar a produtividade sistêmica da economia brasileira e galgar mais um degrau rumo à modernização.

Os impactos negativos verificaram-se, por um lado, com o aprofundamento de dependências estruturais e, por outro, com o regresso histórico. Dando razão aos estruturalistas latino-americanos, que assentavam planos de ação sobre objetivos de longo prazo, os normais, com seus choques de mercado, fizeram ressurgir 
dependências que os primeiros haviam identificado e combatido. As dependências financeira, empresarial e tecnológica, promovidas novamente, elevaram a vulnerabilidade externa do país a níveis críticos. Ao empurrar, ademais, a economia nacional para o setor primário, onde a mantiveram os liberais-conservadores da Independência a 1930, regredia-se, de certo modo, ao século XIX.

O paradigma do Estado normal, em suma, foi o caminho aberto pela inteligência política latino-americana nos anos 1990. Todos os governos se dispuseram a trilhá-lo à galope, mas não o fizeram no mesmo ritmo e com a mesma coerência. Em toda parte, o paradigma revelava seus três parâmetros essenciais: subserviência na esfera política, destruição na esfera econômica e regresso do ponto de vista estrutural e histórico.

Dentre os grandes Estados da região, a Argentina de Menem pode ser tomada como protótipo de aplicação daqueles parâmetros, enquanto o Brasil de Cardoso manifestou as maiores hesitações quanto ao ritmo e à coerência a adotar diante do novo modelo de inserção internacional. A coexistência paradigmática, embora possa parecer paradoxal ao analista, concretizou-se na era Cardoso, dominada por um homem, cuja personalidade sempre revelou incoerências teóricas e hesitações operacionais. Cardoso ofereceu o espetáculo da dança dos paradigmas: o desenvolvimentista, que agonizava mas não morria, o normal, que emergia de forma prevalecente, e o logístico, que se ensaiava ao mesmo tempo ${ }^{11}$.

\section{O paradigma do Estado logístico}

A introdução do paradigma logístico durante a era Cardoso não passou de um ensaio. Assim mesmo, podemos conceituá-lo, do mesmo modo que o fizemos para os outros três, extraindo, porém, da reflexão certos elementos que os dirigentes deixam de fornecer com sua timidez operacional. Antes de tudo, convém dirigir a atenção para possíveis explicações que se encontrem na origem do modelo de inserção internacional que se mesclava com os outros dois. Nosso esforço chega a três considerações.

Em primeiro lugar, o malogro das experiências neoliberais latino-americanas fazia-se prever desde sua instalação no início da década de 1990. Claramente pelos seus críticos, na forma de dúvida por outros. Foi confirmado, doze anos depois, por estudos que avaliaram os resultados das experiências ${ }^{12}$. Relatórios da Cepal revelaram que 43\% da população latino-americana, cerca de 280 milhões, viviam em níveis de pobreza em 2003. Na passagem do milênio, a opinião pública derrubava, pela via eleitoral, os governos de perfil neoliberal. Por outro lado, durante a fase de experiências neoliberais, os políticos jogavam à opinião pública apreciações contraditórias acerca da globalização, o conceito de globalização benigna, pregada pela comunidade epistêmica que assessorou o governo de Menem, e de 
globalização assimétrica, uma consistente teoria elaborada pelo eclético Fernando Henrique Cardoso, que a divulgava em escritos, entrevistas e discursos.

Em segundo lugar, percebiam os dirigentes brasileiros que seus colegas do centro não procediam do mesmo modo, ou seja, não aplicavam em sua gestão pública os preceitos que passavam à periferia latino-americana. $\mathrm{O}$ intrigante exemplo de comportamento político, observado tanto nas decisões internas quanto nos foros multilaterais onde se construía o ordenamento econômico global, levantava dúvidas quanto ao acerto de se aplicar as instruções neoliberais. Por que não imitar aquele tipo de comportamento dos poderosos?

Uma terceira explicação para a introdução do paradigma logístico residia na sobrevivência do pensamento crítico no Brasil e em toda a América Latina. Com efeito, esse pensamento crítico, de reconhecimento tardio, era explícito e consistente ao ponto de podermos considerar uma postura ideológica o termo pensamento único, aplicado aos liberais radicais. Na Argentina, o pensamento crítico confrontava a comunidade epistêmica nas Universidades, na imprensa e nas livrarias e contava com intelectuais de peso como Aldo Ferrer, Mario Rapoport, Roberto Lavagna e Raúl Bernal-Meza. No México, exibiam-se as obras de Osvaldo Sunkel ${ }^{13}$.

No Brasil, seja-nos permitido referir duas manifestações do pensamento crítico. Dentro do próprio Itamaraty, o modelo normal de inserção internacional implementado pelo governo Cardoso não recolhia a unanimidade do pensamento diplomático. Alguns expoentes embaixadores do quadro, a exemplo de Rubens Ricupero, Celso Amorim e Samuel Pinheiro Guimarães, lançavam dúvidas acerca do acerto das decisões na área externa. Especialmente este último, enquanto dirigiu o Instituto de Pesquisa de Relações Internacionais do Itamaraty, promoveu inúmeros encontros, reunindo estudiosos e empresários, e lançou algumas séries de livros que evidenciavam a crítica ao paradigma que impregnava o processo decisório em relações internacionais ${ }^{14}$.

$\mathrm{Na}$ academia, por outro lado, um grupo de estudiosos das relações internacionais da Universidade de Brasília, recentemente denominado Escola de Brasília por Bernal-Meza, difundia severas interpretações, em seminários, salas de aula, livros e por meio da Revista Brasileira de Política Internacional ${ }^{15}$. Nesse ambiente, onde prevalecia o pensamento crítico sem fazer a unanimidade, desenvolvemos nossos próprios trabalhos, ao lado de Luiz Alberto Moniz Mandeira, José Flávio Sombra Saraiva, Argemiro Procópio Filho, Antônio Carlos Moraes Lessa, Antônio Augusto Cançado Trindade, Alcides Costa Vaz, Estêvão Chaves de Rezende Martins, Antônio Jorge Ramalho da Rocha, Carlos Roberto Pio da Costa Filho.

O pensamento crítico não postulava o retorno puro e simples do paradigma desenvolvimentista, embora disso eram acusados seus cultores, de forma por vezes grotesca, pela equipe de Cardoso, que os qualificava de saudosistas e neoburros. 
Julgava conveniente, contudo, para a formação nacional, transitar do paradigma desenvolvimentista ao logístico, e não tomar o caminho normal, mergulhando na subserviência, destruição e regresso.

Recorremos, mais uma vez, aos dois componentes do bloco mental, ideologia e política, com o objetivo de identificar e esclarecer os parâmetros da estratégia logística.

A ideologia subjacente ao paradigma do Estado logístico associa um elemento externo, o liberalismo, a outro interno, o desenvolvimentismo brasileiro. Funde a doutrina clássica do capitalismo com o estruturalismo latino-americano. Admite, portanto, manter-se na ordem do sistema ocidental, recentemente globalizado.

Na esfera política, o paradigma logístico, como experiência brasileira ou latino-americana, comprova uma criatividade ainda maior. Recupera a autonomia decisória, sacrificada pelos normais, e adentra pelo mundo da interdependência implementando um modelo decisório de inserção autônoma. Seu escopo final, a superação de assimetrias entre as nações, ou seja, elevar o patamar nacional ao nível das nações avançadas. Diferencia-se do paradigma desenvolvimentista, com o qual convive sem conflito, ao transferir à sociedade as responsabilidades do Estado empresário. Diferencia-se do normal, consignando ao Estado não apenas a função de prover a estabilidade econômica, mas a de secundar a sociedade na defesa de seus interesses, na suposição de que não convém sejam simplesmente entregues às leis do mercado. Por fim, o Estado logístico imita o comportamento das nações avançadas, particularmente os Estados Unidos, visto como protótipo do modelo. A política exterior volta-se à realização de interesses nacionais diversificados: dos agricultores, combatendo subsídios e protecionismo, porque convém à competitividade do agronegócio brasileiro; dos empresários, amparando a concentração e o desenvolvimento tecnológico; dos operários, defendendo seu emprego e seu salário; dos consumidores, ampliando seu acesso à sociedade do bem-estar.

A percepção dos interesses brasileiros pelos dirigentes logísticos equivale à percepção de interesses de uma sociedade avançada. Eles julgam necessária, possível e conveniente a introdução de remédios de equilíbrio à interdependência global, por modo a transitar da dependência estrutural à interdependência real.

No campo das relações econômicas internacionais, o comportamento logístico se depara, primeiramente, com o desafio de remover entulhos operacionais acumulados pela estratégia do liberalismo radical: atenuar a dependência tecnológica e financeira, promovendo a inovação produtiva e a saída da condição de esmoleiro internacional. Com isso, restringir a vulnerabilidade externa.

O desafio criativo consiste em reforçar o núcleo econômico duro nacional, por modo a alçá-lo em termos comparativos ao núcleo forte de nações avançadas e a abrir o caminho a sua internacionalização. Com efeito, o paradigma 
desenvolvimentista havia nacionalizado a economia internacional, reunindo, porém, ao termo de sessenta anos, as três condições para internacionalizar certos setores de atividade: grande mercado, disponibilidade de capital e competitividade empresarial. Não fosse a hecatombe normal que se abateu sobre o núcleo forte de matriz nacional, a lógica da História poderia haver triunfado, e o Brasil transitado do paradigma desenvolvimentista para o logístico, desde 1990.

Como vimos, o reforço do núcleo duro nacional supõe, no padrão logístico, o repasse de responsabilidades do Estado empresário à sociedade. Não lhe repugna, contudo, o empreendimento estatal, conquanto este eleve seu desempenho ao nível de competitividade sistêmica global. Mas seu foco consiste, precisamente, em dar apoio logístico aos empreendimentos, público ou privado, de preferência privado, com o fim de robustecê-lo em termos comparativos internacionais. Assim procedem os governos dos países centrais - Estados Unidos, Europa e Japão, a título de exemplos - protegendo empresas, tecnologia e capitais de matriz nacional, estimulando seu fortalecimento interno e sua expansão global, zelando pelo emprego e pelo bom salário dos trabalhadores, ampliando o bem-estar do consumidor.

O comportamento do Estado logístico, como se percebe, descola-se da teoria estruturalista e se aproxima dos requisitos da teoria realista das relações internacionais. Supõe concluída a fase desenvolvimentista e projeta nova etapa. Põe em marcha dois componentes de conduta advogados pelos realistas: a construção de meios de poder e sua utilização para fazer valer vantagens comparativas, não mais as naturais, mas as de natureza intangível, como a ciência, a tecnologia e a capacidade empresarial.

Os impactos do ensaio de paradigma logístico sobre a formação nacional, durante a era Cardoso, não foram desprezíveis. Situam-se mais do lado da esperança do que da vida real. Criaram-se expectativas de viabilidade de grandes empreendimentos nacionais, nas áreas de mineração e siderurgia, energia, indústria aeronáutica, tecnologia espacial e nuclear, indústria alimentícia e outras. Vislumbrouse, ademais, a possibilidade da transição do paradigma desenvolvimentista ao logístico, sugerida pela racionalidade histórica. Realizavam-se, em certa doze, expetativas de ingresso na sociedade madura do sistema capitalista, induzida pelo comportamento dos grandes que se procurava imitar. Sonhava-se com o nivelamento pelo alto do bem-estar social e do desenvolvimento econômico. Iniciava-se a internacionalização econômica, sobretudo pela vizinhança, concebida, enfim, como remédio aos desequilíbrios estruturais.

\section{Conclusão}

Os dirigentes do governo de Luiz Inácio Lula da Silva, inaugurado em 2003, contemplam três estratégias de inserção internacional postas em marcha pelos governos brasileiros, com maior ou menor apoio social, entre 1930 e 2002. 
Nosso estudo procurou, para cada uma delas, esclarecer as origens, identificar os componentes mentais e materiais e avaliar os impactos sobre a formação nacional. Esse esforço de reflexão nos conduziu à invenção de conceitos e a sua articulação no que poderíamos denominar teoria paradigmática das relações internacionais do Brasil.

Os estudos de relações internacionais que se expandem no país desde 1990 haverão de checar a consistência ou a fragilidade de nossos conceitos, alargando, como convém, o campo de observação empírica sobre os quais se assentam. As relações internacionais do Brasil constituem por todos os títulos um laboratório de experiências históricas ricas e variadas. Agregam correntes fortes de pensamento e estratégias de ação criativas. Que sejam iluminadas por conceitos e teorias elaborados nos centros de estudo do norte desenvolvido, não por modo a reproduzi-los na área cognitiva, de forma acrítica, muito menos por modo a operacionalizá-los na esfera dirigente, de forma subserviente. Convém ao estudo e ao comportamento político, em nosso entender, destilar o conhecimento alheio na química do pensamento brasileiro e latino-americano com o fim de aprofundar o conhecimento de nossa própria realidade e nos habilitar a implementar estratégias de ação que conduzam a bom termo o processo de desenvolvimento.

Outubro de 2003

\section{Notas}

1 SARAIVA. José Flávio Sombra. Relações internacionais. Dois Séculos de História. Brasília: IBRI, 2001, 2 v.

2 HUNTINGTON, Samuel. The Clash of Civilizations and the Remaking of the World Order. New York: Simon and Schuster, 1996. JERVIS, Robert. Cooperation under the Security Dilemma. Wold Politics, v. 30, n. 2, Jannuary 1978, p. 167-214.

3 BERNAL-MEZA, Raúl. Teoría de relaciones internacionales: el pensamiento latinoamericano (originais cedidos pelo autor). Cf. CERVO, Amado Luiz. A política exterior da Argentina: 1945-2000. In: Guimarães, S. P. Argentina: visões brasileiras. Brasília: IPRI, 2000, p. 11-88.

4 CERVO, Amado Luiz. Relações internacionais da América Latina: velhos e novos paradigmas. Brasília: IBRI, 2001. CERVO, Amado Luiz \& BUENO, Clodoaldo. História da política exterior do Brasil. Brasília: EdUnB, 2002. CERVO, Amado Luiz (org.) O desafio internacional; a política exterior do Brasil de 1930 a nossos dias. Brasília: EdUnB, 1994. CERVO, Amado Luiz \& RAPOPORT, Mario (orgs.). História do Cone Sul. Rio de Janeiro: Revan, 1998. Ver abordagem similar desenvolvida por Celso LAFER em seu livro Aidentidade internacional do Brasil: passado, presente e futuro (São Paulo: Perspectiva, 2001).

5 WATSON, Adam. The evolution of international society: a comparative historical analysis. London and New York: Routledge, 1992. BULL, Hedley \& WATSON, Adam. L’espansione della società internazionale. Milano: Jaca Book, 1994. Ver a longa apresentação de Brunello Vigezzi sobre o trabalho do British Committee on the Theory of International Politics, p. XI-XCVIII. 
Ver CERVO, Amado Luiz. O parlamento brasileiro e as relações exteriores (1826-1889). Brasília: Ed. Univ. de Brasília, 1981.

7 Pequena bibliografia sobre o período: LUZ, Nícia Vilela. A luta pela industrialização no Brasil (1808-1930). São Paulo: Difel, 1978. GOES FILHO, Synesio Sampaio. Navegantes, bandeirantes, diplomatas: um ensaio sobre a formação das fronteiras do Brasil. São Paulo: Martins Fontes, 1999. MAGNOLI, Demétrio. O corpo da pátria. São Paulo: UNESP, 1997. FREITAS, Caio de. George Canning e o Brasil. São Paulo: Ed. Nacional, 1958, 2 v. GRAHAM, Richard. Grã-Bretanha e o início da modernização no Brasil. São Paulo: Brasiliense, 1973. MANCHESTER, Alan K. Preeminência inglesa no Brasil. São Paulo: Brasiliense, 1973. BANDEIRA, Moniz. O expansionsimo brasileiro. Rio de Janeiro: Philobiblion, 1985. ALMEIDA, Paulo Roberto de. Formação da diplomacia econômica no Brasil: as relações econômicas internacionais no Império. São Paulo: Senac, 2001. BUENO, Clodoaldo. A República e sua política exterior (1889-1902). Marília: UNESP; Brasília, IPRI, 1995. BUENO, Clodoaldo. A política externa da Primeira República: os anos de apogeu. Rio de Janeiro: Paz e Terra, 2003. GARCIA. Eugênio Vargas. O Brasil e a Liga das Nações (1919-1926). Porto Alegre: Ed. da Universidade, 2000.

Pequena bibliografia sobre o período: ABREU, Marcelo de Paiva. O Brasil e a economia mundial (1929-1945). In: Fausto, B. (org.) História geral da civilizaçao brasileira. São Paulo: Difel, 1984, v. 11, p. 9-49. MOURA, Gerson. Autonomia na dependência; a política externa brasileira de 1935 a 1942. Rio de Janeiro: Nova Fronteira, 1980. Idem. Sucessos e ilusões; relações internacionais do Brasil durante e após a Segunda Guerra Mundial. Rio de Janeiro: Fundação Getúlio Vargas, 1991. SEITENFUS, Ricardo A. S. O Brasil de Getúlio Vargas e a formação dos blocos (1930-1942). São Paulo: Ed. Nacional, 1985. MALAN, Pedro Sampaio. Relações econômicas internacionais do Brasil (1945-1964). In: Fausto, B. (org.) História Geral da Civilização Brasileira. São Paulo: Difel, 1984, v. 11, p. 51-106. VIANNA, Sérgio B. A política econômica no segundo governo Vargas (19511954). Rio de Janeiro: BNDS, 1987. BANDEIRA, Moniz. Brasil-Estados Unidos; a rivalidade emergente (1950-1988). Rio de Janeiro: Civ. Brasileira, 1990. Idem. Estado nacional e política internacional na América Latina (1930-1992). São Paulo: Ensaio, 1993. Idem. Brasil, Argentina e Estados Unidos. Da Tríplice Aliança ao Mercosul (18702003). Rio de Janeiro: Revan, 2003. DREIFUSS, R. A. A internacional capitalista; estratégia e táticas do empresariado transnacional (1918-1986). Rio de Janeiro: Espaço e Tempo, 1987. SELCHER, Wayne A. Brazil's multilateral relations between First and Third Worlds. Boulder: Westview Press, 1978. STORRS, K. L. Brazil's independent foreign policy (1961-1964). Cornell Univ. Dissertation, 1973. MANZUR, Tânia M. P. G. Opinião pública e política exterior nos governos de Jânio Quadros e João Goulart (1961 a 1964). Universidade de Brasília, tese de doutorado, 2000. VIZENTINI, Paulo G. F. Relações internacionais e desenvolvimento: o nacionalismo e a política externa independente (1951-1964). Petrópolis: Vozes, 1995. Idem. A política externa do regime militar brasileiro (1964-1985). Porto Alegre: Ed. da Universidade, 1998. ALBUQUERQUE, José A. Guilhon (org.). Sessenta anos de política externa brasileira. São Paulo: USP. 1996-, 4 v. DANESE, Sérgio F. Diplomacia presidencial. Rio de Janeiro: Topbooks, 1999.

CARDOSO, Fernando Henrique. Política externa em tempos de mudança. Brasília: FUNAG, 1994. LAFER, Celso. Mudam-se os tempos: diplomacia brasileira, 2001-2002. Brasília: FUNAG, 2002.

10 Ver, entre outras obras de Gilbeto DUPAS: Tensões contemporâneas entre o público e o privado. Rio de Janeiro: Paz e Terra, 2003; O Brasil e as novas dimensões da segurança internacional. São Paulo: Alfa-Omega, 1999. Economia global e exclusão social. Paz e Terra, várias edições. 
11 CERVO, Amado Luiz. Relações internacionais do Brasil: um balanço da era Cardoso. Revista Brasileira de Política Internacional, ano 45, n. 2, 2002, p. 5-35.

12 BANDEIRA, Luiz Alberto Moniz. As políticas neoliberais e a crise da América Latina. Revista Brasileira de Política Internacional, ano 45, n. 2, p. 135-146, 2002. CERVO, Amado Luiz. Sob o signo neoliberal: as relações internacionais da América Latina. Revista Brasileira de Política Internacional, ano 43, n. 2, p. 5-27, 2000.

13 Um balanço de suas obras em Raúl Bernal-Meza, Teoria das relações internacionais, cit.

14 Ver as publicações da FUNAG, Ministério das Relações Exteriores.

15 Ver a coleção Relações Internacionais, de dez volumes, organizada por José Flávio Sombra Saraiva, e publicada pelo Instituto Brasileiro de Relações Internacionais, entre 2001-2003. Ver também as coleções da Editora da UnB, Relações Internacionais, por nós organizada, e O Brasil e o Mundo, por Saraiva.

\section{Resumo}

O artigo analisa a inserção internacional dos países latino-americanos no período que se inicia nos princípios do século XIX chegando até os nossos dias. Tendo como base principalmente o caso brasileiro, mas não deixando de comentar as experiências argentina e mexicana, o autor identifica e descreve os quatro paradigmas norteadores da formulação da política externa desses países ao longo desses dois séculos.

\section{Abstract}

The article analyzes the iternational insertion of Latin-American countries during the time-period that starts in the beginning of the $19^{\text {th }}$ century up to nowadays. Having Brazil's case as the main basis, and without forgetting to comment the Argentinean and the Mexican experiences, the author traces the four leading paradigms of the prescribed foreign policy of these countries during the last two centuries.

Palavras-chave: Política Externa Brasileira; Desenvolvimento; Dependência. Key words: Brazilian Foreign Policy; Development; Dependence. 